Paper submitted to the $7^{\text {th }}$ Hypervelocity Impact Symposium (HVIS), Galveston, Texas, November 6-10, 2000

\title{
Equation of State Measurements of Materials Using a Three-Stage Gun to Impact Velocities of $11 \mathrm{~km} / \mathrm{s}$
}

\author{
W. D. Reinhart, L. C. Chhabildas, D. E. Carroll, \\ Sandia National Laboratories, Albuquerque, NM 87185 \\ T. G. Thornhill, \\ KTech Corp., Albuquerque, NM 87109 \\ N. A. Winfree, \\ Applied Research Associates, Albuquerque, NM 87110
}

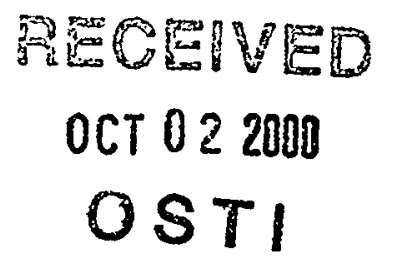

\begin{abstract}
Understanding high pressure behavior of homogeneous as well as heterogeneous materials is necessary in order to address the physical processes associated with hypervelocity impact events related to space science applications including orbital debris impact and impact lethality. At very high impact velocities, material properties will be subjugated to phase-changes, such as melting [1] and vaporization [2]. These phase states cannot be obtained through conventional gun technology. These processes need to be represented accurately in hydrodynamic codes to allow credible computational analysis of impact events resulting from hypervelocity impact. In this paper, techniques that are being developed and implemented to obtain the needed shock loading parameters (Hugoniot states) for material characterization studies, namely shock velocity and particle velocity, will be described at impact velocities up to $11 \mathrm{~km} / \mathrm{s}[3,4]$. What is new in this report is that these techniques are being implemented for use at engagement velocities never before attained utilizing two-stage light-gas gun technology $[5,6]$.
\end{abstract}

\section{Introduction}

Historically, suites of diagnostics and experimental techniques have been used to measure high-pressure, high temperature material properties resulting from impact [7]. These techniques have allowed measurements of the shock-Hugoniot, shock-loading and release behavior, material strength, shock-induced melting, and shock-induced vaporization processes in materials. All these techniques have realized material properties to form databases to develop constitutive models to represent material behavior under dynamic loading. Titanium alloy, specifically, Ti$6 \mathrm{Al}-4 \mathrm{~V}$, is used in these studies mainly because it is known to be fracture resistant and has been launched intact to $16 \mathrm{~km} / \mathrm{s}$. This same alloy is therefore being characterized as a standard material for use as the flyer-plate in this study. The existence of an accurate database for use as a well-known standard material will facilitate the equation-of-state (EOS) development of other engineering materials, particularly those used in space applications. This technique allows development of equation-of-state data and models of materials never before laboratory tested at impact velocities exceeding $11 \mathrm{~km} / \mathrm{s}$

Symmetric impact experiments, conducted at impact velocities of $11.2 \mathrm{~km} / \mathrm{s}$ introduce a shock up to a stress level of approximately $300 \mathrm{GPa}$ in this alloy. Impact velocity of the flyerplate is determined radiographically and by interferometric, VISAR (Velocity Interferometer System for Any Reflector), techniques. The VISAR [8] measures the flyer-plate acceleration 


\section{DISCLAIMER}

This report was prepared as an account of work sponsored by an agency of the United States Government. Neither the United States Government nor any agency thereof, nor any of their employees, make any warranty, express or implied, or assumes any legal liability or responsibility for the accuracy, completeness, or usefulness of any information, apparatus, product, or process disclosed, or represents that its use would not infringe privately owned rights. Reference herein to any specific commercial product, process, or service by trade name, trademark, manufacturer, or otherwise does not necessarily constitute or imply its endorsement, recommendation, or favoring by the United States Government or any agency thereof. The views and opinions of authors expressed herein do not necessarily state or reflect those of the United States Government or any agency thereof. 


\section{DISCLAIMER}

Portions of this document may be illegible in electronic image products. Images are produced from the best available original document. 
history which can be used to estimate the thermodynamic state of the flyer-plate prior to impact; in other words, the temperature of the flyer-plate. This will be discussed later in the paper.

Until recently the highest-pressure states in materials have been achieved from impact loading techniques from two-stage light gas guns with velocity limitations of approximately $8 \mathrm{~km} / \mathrm{s}$. The determination of EOS and thermodynamic states of materials in the regimes of extreme high pressures is now attainable utilizing the three-stage launcher. The implementation of this technique described in this paper will facilitate the EOS database that is needed for use with hydrodynamic codes.

\section{History of the Three-Stage Launcher}

The three stage-light gas-gun, also referred to as the hypervelocity launcher, was developed in the early nineties [9]. Since then its capabilities have been enhanced to achieve higher engagement velocities up to $16 \mathrm{~km} / \mathrm{s}[2,4]$. A variety of experimental techniques have also been developed for use with applications such as shock-induced vaporization studies [2] or to assess impact damage to substructures [10]. In these early investigations, experimental transit times were in the range of 1 microsecond to over 100 microseconds after impact. The experimental studies in the above investigations do not require a high degree of precision to obtain high accuracy.

Previous shock loading and release studies on aluminum and titanium alloy at impact velocities of $10 \mathrm{~km} / \mathrm{s}$ [1] emphasized the need to implement experimental techniques that required a much higher degree of precision in support of EOS studies. It is the purpose of this paper to describe the methods that have been employed to achieve a higher precision needed for EOS studies. These techniques also allow an assessment on the flyer-plate conditions prior to impact such as tilt, bow, impact velocity and the thermodynamic state of the flyer, namely its density and temperature prior to impact.

The Sandia hypervelocity launcher, the three-stage gun, is briefly described here. A twostage projectile is accelerated and impacts a stationary flyer-plate (Figure 1a), which is subsequently launched at velocities from $8 \mathrm{~km} / \mathrm{s}$ to greater than $11 \mathrm{~km} / \mathrm{s}$ depending on the twostage light-gas gun (TSLGG) projectile impact velocity. The loading pressure pulse on the flyer-plates must be uniform and time-dependant to prevent the melting or vaporization of the

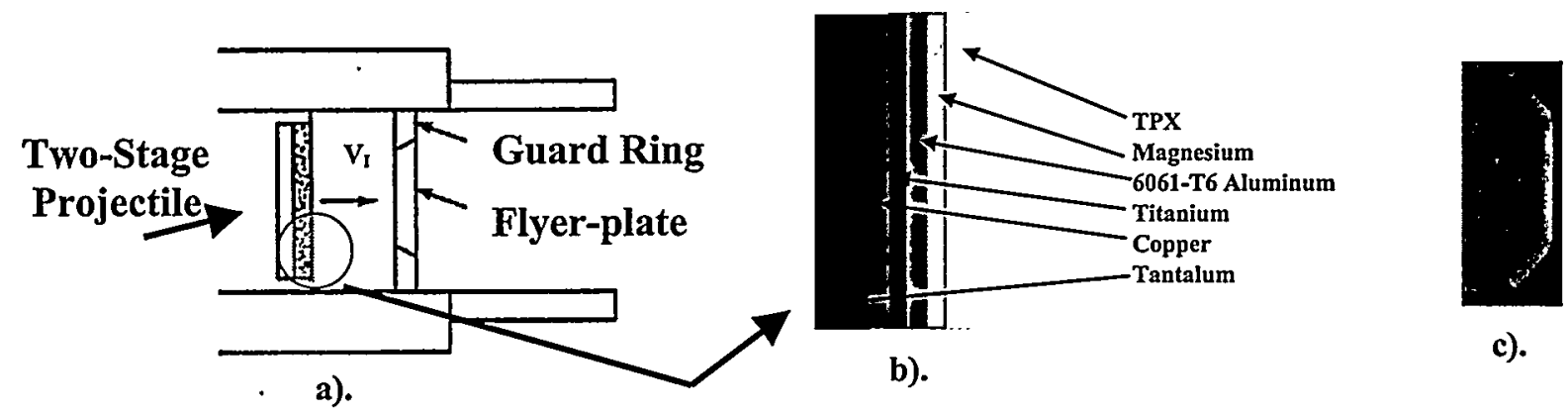

Figure 1 (a) Two-stage projectile and third stage flyer-plate configuration. (b) Graded density impactor with TPX facing impacting the stationary flyer-plate. (c) X-ray radiograph of typical threestage flyer-plate traveling at $11.1 \mathrm{~km} / \mathrm{s}$.

flyer-plate. To accomplish time-dependent loading, carefully designed graded-density materials $[11,12,13]$ on the TSLGG projectile are used. When this graded-density assembly, shown in 
Figure 1(b), is used to impact a flyer-plate, the time-dependant pressure pulse introduces nearly shockless, megabar pressures into the flyer-plate $[6,12,13]$.

This pressure pulse must also be tailored to prevent spallation of the flyer-plate. This technique is now routinely used to launch $17-19 \mathrm{~mm}$ diameter, $0.6 \mathrm{~mm}$ to $1.0 \mathrm{~mm}$ thick titanium flyers to better than $11 \mathrm{~km} / \mathrm{s}$ and a typical flyer-plate (radiograph) is shown in Figure 1(c).

\section{Two-Stage Projectile}

The TSLGG projectile for these experiments is an integral part of the technique to launch plates to high velocities and subsequently used to obtain EOS data at extremely high pressures. The projectile velocity must be known to better than $0.2 \%$, the graded density impactor must be intact, and the tilt of the projectile upon impact must be small for proper three-stage flyer-plate launch.

The projectile velocity is measured using a new technique call the Optical Beam Reflectance (OBR) system (Figure 2a). In these studies, five (5) fiber probes (indicated in Figure 1a) are located in the barrel extension with approximately $57 \mathrm{~mm}$ separation, and overall separation of about $228 \mathrm{~mm}$. The dimension of each station segment is known to $0.025 \mathrm{~mm}$. The output of the OBR is shown in Figure 1b (three outputs - typical - are shown from a low velocity shot). The transit time of approximately $20 \mu$ s between each station is determined to better than 2 ns. The implementation of this system clearly allows projectile velocity determination [27] to better than $0.2 \%[14,15,16]$.
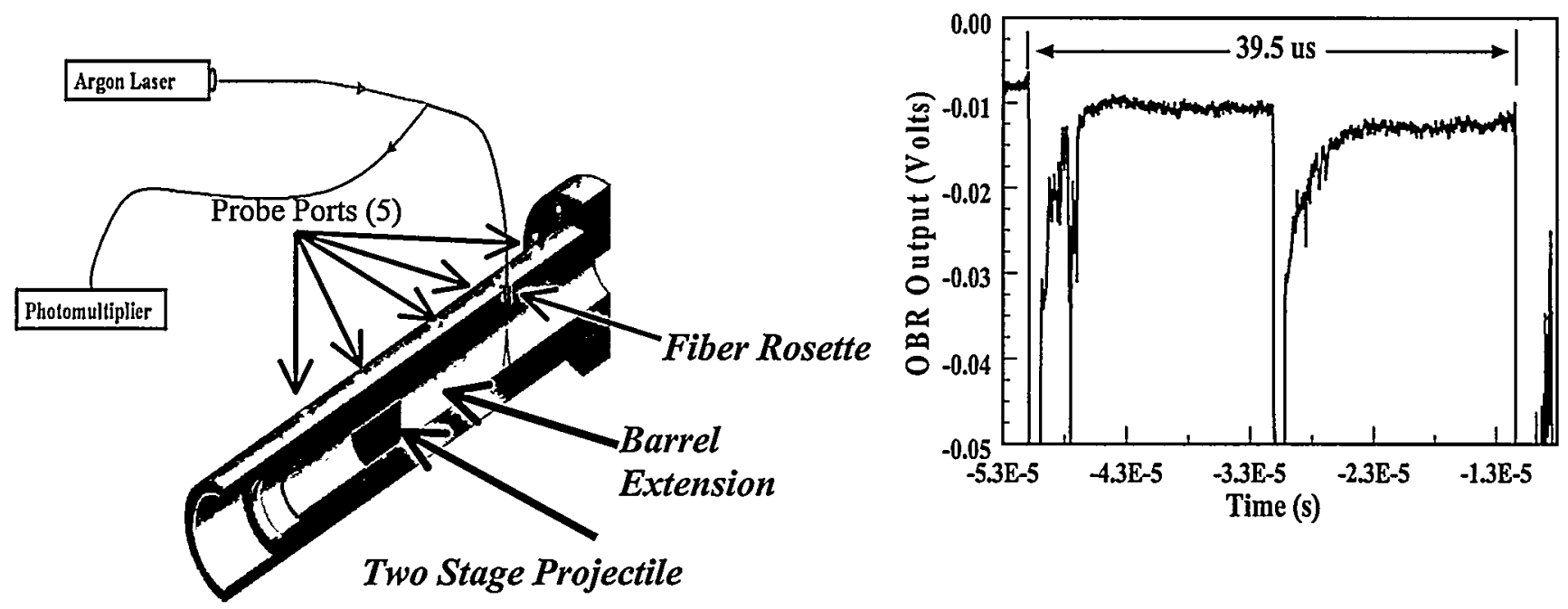

Figure 2 Cut away drawing of the OBR system. System is shown only for one port. Typical OBR output signals.

The OBR concept shown in Figure 2a uses a fiber bundle, a photomultiplier tube, laser and recording system. The fiber probe in has a 200um center fiber surrounded by nine $100 \mathrm{um}$ fibers. The larger centered fiber is aligned [14,27] to transmit the laser light while the surrounding smaller nine fibers collect the reflected light from the moving projectile and is 
transmitted to the recording system. All return fiber outputs are coupled into the photomultiplier tube, which reduces timing and risetime uncertainties.

\section{Flyer-plate:}

Following the launch, to obtain the EOS data the flyer must be intact, flat, the thermodynamic state known, and the velocity must also be well known for use in planar impact experiments. The determination of the flyer-plate impact velocity is crucial for obtaining accurate EOS measurements. As described above, the graded density impactor on the two-stage projectile is used as an impactor to accelerate a stationary flyer-plate to velocities greater than 11 $\mathrm{km} / \mathrm{s}$. For typical light gas gun operations, impact velocity is easily attainable to an accuracy better than $0.2 \%$. In this study the methodology used to determine and estimate the flyer-plate impact velocity is described below.

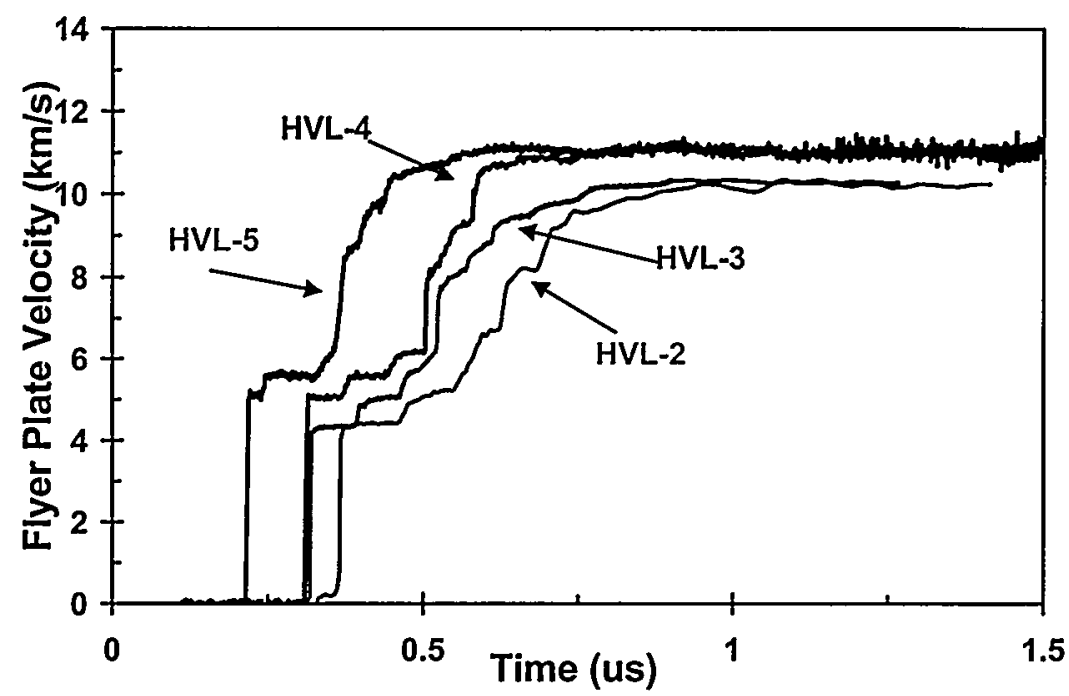

Figure 3. VISAR profiles mapping flyer-plate acceleration history.

A series of experiments were conducted to map the acceleration history of the flyer-plate using a velocity interferometer (VISAR). In addition, flash radiography was also used to determine the terminal velocity. Typical velocity profiles obtained (Figure 3), map the entire acceleration history prior to achieving terminal velocity. $\mathrm{X}$-ray measurements of the flyer-plate velocity were also determined over propagation distances of about $250 \mathrm{~mm}$. These flyer-plate velocity measurements using VISAR and radiography are shown in Table I. Based on the fringe sensitivity used in the velocity interferometer, the terminal flyer-plate velocity is determined to a precision better than $0.6 \%$. The X-ray measurements over the distances previously mentioned, indicate a precision in velocity measurements to better than $0.2 \%$.

In these experiments, the exact dimension of the graded-density material is known. Also, the TSLGG projectile velocity is measured to precision better than $0.1 \%$. The impact velocity, dimensions of the graded density assembly on the projectile and the flyer-plate dimensions were then input into the finite difference hydrodynamic code, $\mathrm{CTH}$, to calculate the flyer-plate velocity. As indicated in Table I, the results of the code calculation for the flyer-plate velocity agree remarkably well (approximately $1 \%$ for most tests) with the experimental measurements. 
Table I. Comparison of calculated and experimental flyer plate velocity. The dimensions of the graded-density materials and is impact velocity is also indicated.

\begin{tabular}{|c|c|c|c|c|c|}
\hline Test & $\begin{array}{c}\text { Graded Density Impactor Dimensions } \\
\text { (TPX / Mg / Al / Ti / Cu / Ta ) } \\
(\mathrm{mm})\end{array}$ & $\begin{array}{c}\text { Two-Stage } \\
\text { Projectile } \\
\text { Velocity } \\
(\mathrm{km} / \mathrm{s})\end{array}$ & $\begin{array}{c}\text { VISAR } \\
\text { Flyer-plate } \\
\text { Velocity } \\
(\mathrm{km} / \mathrm{s})\end{array}$ & $\begin{array}{c}\text { Xray } \\
\text { Flyer- } \\
\text { plate } \\
\text { Velocity } \\
(\mathrm{km} / \mathrm{s})\end{array}$ & $\begin{array}{c}\text { CTH } \\
\text { Flyer-plate } \\
\text { Velocity } \\
(\mathrm{km} / \mathrm{s})\end{array}$ \\
\hline HVLTi-2 & $1.021 / 0.609 / 0.483 / 0.376 / 0.312 / 1.089$ & 6.33 & 9.80 & ND & 9.71 \\
\hline HVLTi-3 & $0.842 / 0.479 / 0.404 / 0.323 / 0.254 / 0.744$ & 6.74 & 10.23 & 10.50 & 10.49 \\
\hline HVLTi-4 & $0.807 / 0.445 / 0.414 / 0.315 / 0.264 / 0.757$ & 7.22 & 11.04 & 11.05 & 11.13 \\
\hline HVLTi-5 & $0.513 / 0.310 / 0.480 / 0.226 / 0.152 / 0.528$ & 7.32 & 11.15 & 11.24 & 11.25 \\
\hline
\end{tabular}

The agreement between the experiments and calculations is approximately $1-2 \%$, (for the series of experiments conducted to characterize the flyer-plate acceleration histories) and is within the accuracy of the plate-velocity measurements. The impact velocity for the EOS experiments were therefore calculated using the CTH code and the known dimensions of the flyer-plate, graded-density impact materials, and the impact velocity of the two-stage gun projectile (Table II).

Table II. Experimental parameters for the graded-density assembly used to launch flyer-plates for the EOS experiments. The calculated flyer-plate velocity based on CTH code is also shown.

\begin{tabular}{|c|c|c|c|}
\hline Test & $\begin{array}{c}\text { Graded Density Impactor Dimensions } \\
\text { (TPX / Mg / Al / Ti / Cu / Ta ) } \\
(\mathrm{mm})\end{array}$ & $\begin{array}{c}\text { Two-Stage } \\
\text { Projectile } \\
\text { Velocity }(\mathrm{km} / \mathrm{s})\end{array}$ & $\begin{array}{c}\text { CTH } \\
\text { Flyer-plate Velocity } \\
(\mathrm{km} / \mathrm{s})\end{array}$ \\
\hline HVLTi7-P & $0.978 / 0.617 / 0.483 / 0.371 / 0.315 / 1.089$ & 6.28 & 9.50 \\
\hline HVLTi8-P & $0.874 / 0.493 / 0.407 / 0.328 / 0.258 / 0.809$ & 6.69 & 10.40 \\
\hline
\end{tabular}

It is very crucial that the impact velocity of the two-stage projectile be determined to within $0.2 \%$ so that the flyer-plate terminal velocity can be predicted to approximately $1-2 \%$.

Upon impact, edge-release waves emanating from the outer edge of the flyer-plate will decelerate the flyer-plate at its edges. This would have the net effect of introducing a velocity
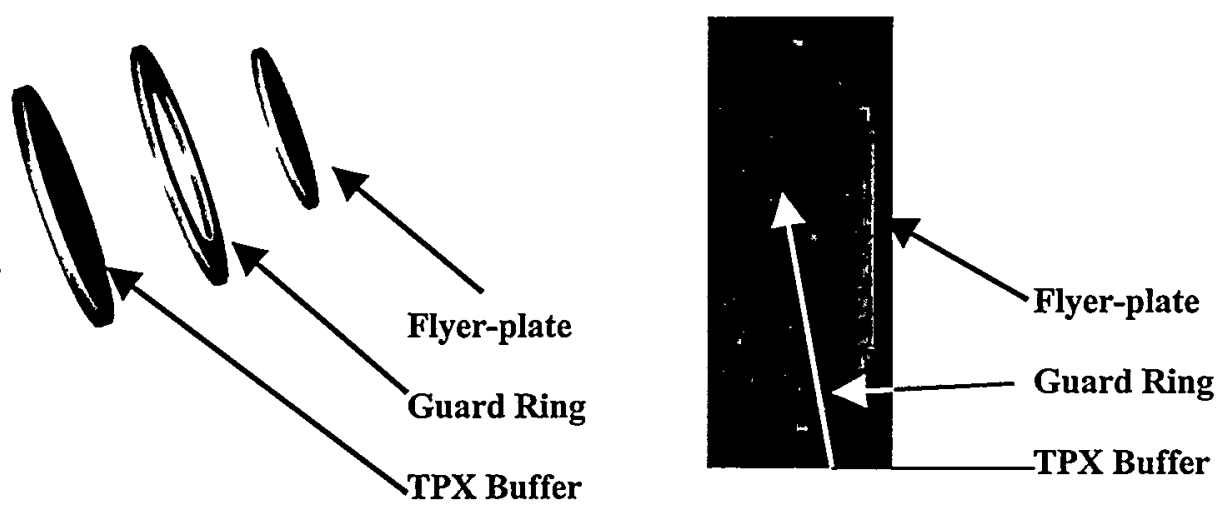

Figure 4. Design of the flyer-plate showing the concept of a guard ring and a concentric flyer. X-ray radiograph indicates the "shape" of the slower moving guard ring, while the flyer-plate traveling at $11.1 \mathrm{~km} / \mathrm{s}$ remains intact and flat. 
gradient during the acceleration phase with the edges moving slower than the terminal velocity. To insure that the flyer-plate is launched intact, the guard ring geometry (shown in Figure 4) is used in all experiments. The guard ring design for the flyer-plated is introduced mainly to prevent the flyer-plate bowing during the acceleration phase. The absence of the guard ring would not only induce bowing-but it would also have the tendency to fracture the plate. The measurement for the tilt and bow of the flyer-plate is discussed in a later section.

As mentioned above, a time-dependent pressure pulse is used to launch the flyer-plate. As a result of using quasi-isentropic compression pressures approaching a megabar, the flyerplate will experience a temperature increase. The temperature of the flyer after launch was first estimated from CTH simulations. These indicated that the temperature in a flyer-plate launched to better than $11 \mathrm{~km} / \mathrm{s}$ and initially at room temperature reached $700 \mathrm{~K}$ when no deviatoric or plastic effects were modeled. When these effects were included in the constitutive models used in the simulation, the temperature in the plated reached an equilibrium value of approximately $1200 \mathrm{~K}$ when the plate reached terminal velocity. Therefore, in this investigation, a warm Ti-6Al$4 \mathrm{~V}$ flyer-plate would impact a Ti-6Al-4V target (300K) at room temperature, calculationaly.

We then used a temperature measuring pyrometer to experimentally measure the surface temperature of a flyer plate during the launch process. Care was taken to shield the pyrometer from stray light. Two experiments were conducted. These indicated, conservatively, that the temperature did not exceed $850 \mathrm{~K}$ when the flyer reached a terminal velocity of $10.4 \mathrm{~km} / \mathrm{s}$, or $650 \mathrm{~K}$ when it reached a velocity of $9.8 \mathrm{~km} / \mathrm{s}$. We chose to use these values, rather than the higher temperature estimate from CTH, as upper bounds for the temperature increase of the flyer. From room temperature $(300 \mathrm{~K})$ to $850 \mathrm{~K}$, the coefficient of linear expansion of Ti-6Al-4V varies nearly linearly from $8.7 \mathrm{e}-06$ to $10.4 \mathrm{e}-06 \mathrm{~mm} / \mathrm{mm} / \mathrm{K}$ and then levels off [19]. For simplicity, we will use $10.4 \mathrm{e}-06 \mathrm{~mm} / \mathrm{mm} / \mathrm{K}$ for all temperatures, recognizing that we will be predicting too great a change in density at temperatures below $850 \mathrm{~K}$. With this value, the predicted densities are 4.368 and $4.341 \mathrm{~g} / \mathrm{cm}^{3}$ at 650 and $850 \mathrm{~K}$, respectively.

In summary, these are technically not symmetric impact experiments. Hence, to use impedance matching techniques for analysis, a Hugoniot for the warm flyer-plate needs to be established to determine the particle velocity in the target plate. In the following, the steps taken to estimate a Mie-Gruneisen equation of state model for Ti-6Al-4V at $1200 \mathrm{~K}$ are described. The same EOS model is used in all experiments in order to estimate the maximum correction required in determining the particle-velocity in the shocked target material.

The CTH distribution contains a SESAME table model of the equation of state of pure titanium includings its vapor, liquid, and solid phases. The BCAT program [17] of the CTH distribution was used to obtain points on the model's prinicpal Hugoniot and on one based at $1200 \mathrm{~K}$ and $0 \mathrm{Gpa}$. The principal Hugoniot was well described by straight line in the Us, up plane;

$$
\mathrm{Us}=\mathbf{c}_{\mathrm{o}}+\mathbf{s} \mathbf{u}_{\mathrm{p}}
$$

where $c_{0}=c_{0}^{C O L D}=4.791 \mathrm{~km} / \mathrm{s}, s=s^{C O L D}=1.242$. The warm material was also well described by a (1) with the parameters

$$
\mathrm{c}_{0}{ }^{\mathrm{w}}=4.715 \mathrm{~km} / \mathrm{s}, \mathrm{s}^{\mathrm{w}}=1.240
$$

From the parameters for the warm and cold material we calculated the correction factors,

$$
\mathbf{r}_{\mathrm{c}}=\mathbf{c}_{0}{ }^{\mathrm{w}} / \mathrm{c}_{\mathbf{0}}{ }^{\text {CoLp }} \text { and } \mathbf{r}_{\mathrm{s}}=\mathrm{s}^{\mathrm{w}} / \mathrm{s}^{\text {COLD }}
$$

for the corresponding $c_{o}$ and $s$ values in equation (1). 
The Hugoniot for Ti-6Al-4V [18] is well described by;

$$
\mathrm{U}_{\mathrm{s}}=4.973+1.111 \mathrm{u}_{\mathrm{p}}
$$

Where $c_{0}=4.973$ and $s=1.111$. It was then assumed that the warm Hugoniot of Ti-6Al-4V based at 0 pressure and $1200 \mathrm{~K}$ would also lie on a straight line. The "new" co and S were estimated by multiplying the intercept $\left(c_{o}=4.973\right)$ by the correction factor $r_{c}$ and the slope $(s=$ 1.111) by $\mathrm{r}_{\mathrm{s}}$, obtaining the relation;

$$
\mathrm{U}_{\mathrm{s}}=4.893+1.109 \mathrm{u}_{\mathrm{p}}
$$

The density of Ti-6Al-4V at $1200 \mathrm{~K}$ is estimated to be $\rho_{0}=4.296 \mathrm{~g} / \mathrm{cm}^{3}$, based on the roomtemperature density $\rho_{0}=4.419 \mathrm{~g} / \mathrm{cm}^{3}$ and the coefficient of linear expansion of Ti-6Al-4V, which is approximately $10.26 \mathrm{e}-06(\mathrm{~mm} / \mathrm{mm} / \mathrm{K})$ above $1140 \mathrm{~K}$ [19].

To summarize, this analysis indicates that the Hugoniot for the warm material can be represented by its new density, at the warm temperature of the plate, and a new coefficient "c". The slope of the $U_{s}-u_{p}$ curve is very nearly the same in each case.

\section{Target Configuration}

In this study, a titanium alloy, Ti-6Al-4V (6\% wt. Aluminum and $4 \% \mathrm{wt}$. Vanadium) was used to establish it as a standard material for EOS investigations. The target was fabricated from Ti-6Al$4 \mathrm{~V}$ as a "two-stepped-target" (Figure 5) and aligned for planar impact from the flyer. As shown in Figure 5, unlike previous studies $(23,24)$, two different sized holes were drilled into the target on two separate diameters. The outer diameter, which is referred to as the " $\mathrm{A}$ " Plane has twelve locations for (6) anodized self-shorting pins and (6) 100um diameter optical fiber "needles".
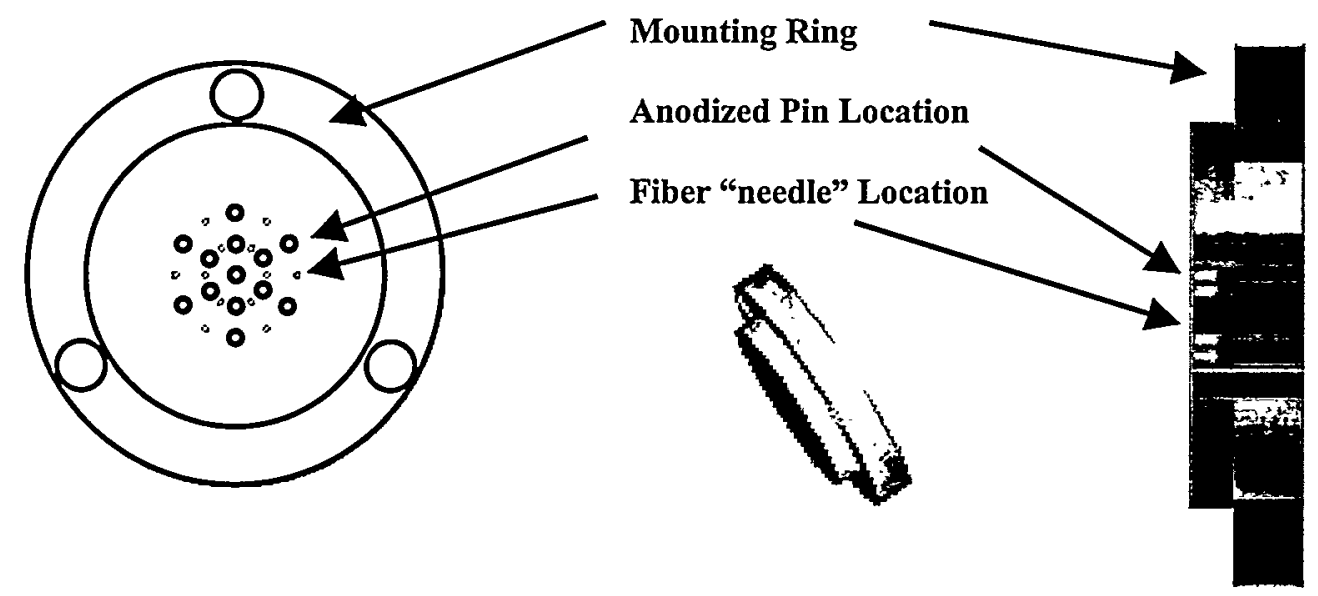

Figure 5. A drawing of the anodized pins and fiber-optic needles target configuration.

The fibers are inserted in a 500um syringe (hence the reference of the fibers as "needles"). The center of the target uses either a pin or a needle, which is on the " $A$ " Plane as well. Inside the A-plane diameter is another twelve pins and needle locations which are distributed over the "B" plane and are located in the same angular positions to that of the A-plane pins and needles.

The pins and needles are inserted into the drilled holes, which have a clearance of about $0.02-0.03 \mathrm{~mm}$. Because of the tight tolerance for the clearance holes and radii dimension call out, the pin radii will vary by less than $0.5 \mathrm{~mm}$ and the fiber radii will be better than $0.1 \mathrm{~mm}$. The angular separation of the pins and needles is $60^{\circ}+1-1^{\circ}$. 
For these experiments, the hole depth is accurately known to within $0.02 \mathrm{~mm}$ and the surface finish uncertainty is approximately $10 \mathrm{um}$. This results in an uncertainty of approximately $1-2 \%$ in estimating the sample depth; i.e.. thickness dimensions.

\section{Shock Velocity Measurements}

The experimental premise for the EOS experiments is determined by the RankineHugoniot relations [20], which are based on the conservation of momentum, mass, and energy across the shock front wave as it travels through matter. These relations are:

$$
\begin{aligned}
& \mathbf{P}-\mathbf{P}_{0}=\rho_{0}\left(U_{s}-u_{0}\right)\left(u_{p}-u_{0}\right) ; \\
& V=V_{0}\left[1-\left(u_{p}-u_{0}\right) /\left(U_{s}-u_{0}\right)\right] ; \\
& E-E_{0}=1 / 2\left(P+P_{0}\right)\left(V_{0}-V\right)
\end{aligned}
$$

where $P_{0}, \rho_{0}, V_{0}, E_{0}$ and $u_{0}$ are, initial pressure, density, specific volume, specific internal energy, and the mass velocity of the material. P, V, E, are the final shock pressure, specific volume, and specific internal energy respectively, and $U_{s}$ is the velocity of the shock wave and $u_{p}$ is the mass velocity behind the shock front. Thereby we have four initial state and five final state variables.

In most instances all of the initial-state variables are known and two of the final state variables are either known or measured. The remaining final-state variables can then be obtained from the Rankine-Hugoniot relations. In these experiments, the initial states $P_{0}, \rho_{0}, E_{o}$ and $u_{o}$ are known. The shock velocity, $U_{s}$, is measured in these experiments and $u_{p}$ is deduced from the impact velocity, since the impact conditions impact conditions are very nearly symmetric. If the experimental conditions were exactly symmetric then the material velocity $\left(u_{p}\right)$ behind the shock front is one-half the impact velocity. However, since the flyer-plate temperature is warmer then the target (which is at room temperature) plate the warm Hugoniot for Ti-6Al-4V is used to determine the material velocity behind the shock in the target plate.

Shock wave velocities are determined by measuring shock transit times over a known distance between two parallel planes in the target. In these experiments, the planes are about $2 \mathrm{~mm}$ apart and shock transit times are of the order of 150-200ns measured with two types of time-of-arrival detectors (anodized pins and needles). All cable lengths and fiber runs are identical to within $0.4 \mathrm{~ns}$ and the recording instrumentation has sub-nanosecond time resolution.

Care was taken to ensure that the location of the pins and needles were such that the edge release disturbance starting from the A-plane pin or needle did not interfere with those detectors on the B-plane. In particular, the target was designed so that the radial distance between the time-of-arrival detectors on the A plane and the $\mathrm{B}$ plane was always appreciably greater than the distance between the two planes. This ensures that edge release waves emanating on the $A$ plane, would not interfere with the arrival of the shock front at the B plane. Two-dimensional simulations of the experimental geometry verified that one-dimensionality plane loading conditions were maintained during the shock transit time between the two planes.

Electrical pins work extremely well at high-pressure regimes attained from conventional TSLGG, and at three stage light-gas gun impact velocities. In addition to the anodized pins, we have utilized fiber-optic "needles" as a passive time of arrival detector. Since the dimensions of the fiber optic cables are smaller than that of the electrical anodized pins, it becomes an ideal 
detector, and has the potential of being employed in smaller diameter samples to measure transit times smaller than those used in this study-and to the same degree of precision

The fibers consist of Polymicro $100 \mu \mathrm{m}$ diameter, pure fused silica core inserted into a $500 \mu \mathrm{m}$ tube and its end coated with a thin metal layer, normally aluminum, thick enough to shield any extraneous light. As the shock front arrives at the tip of the fiber, the fiber luminesces $[21,22]$ and sends a signal to an optical detector at the other end. The optical detectors used for these tests were low-noise photomultiplier units electronically modified to obtain 1ns-rise times. The reasoning for embedding the fiber/needle assembly in the target, as indicated in Figure 5, is to ensure that all of the fibers have the same external configuration. This is significant so that the mechanism of luminesces as the stress front arrives, is identical in all instances. The same holds true for the anodized pins. The pins are placed also in a tight tolerance drilled hole. This shields the pins from extraneous sources such as ionized gases, or ejecta from the material.

Having established shock velocity detectors and utilizing the described target configuration, if impactor and target were perfectly flat and parallel, arrival times on a given plane would occur simultaneously. However, tilt and shock front distortion (bowing of the impactor) will cause the arrival times to be at times quite different-even similar to the transit time between the two planes. To understand arrival times properly, the shape and orientation of the shock front must be known. The data-analysis techniques for shock velocity measurements taking into considerations for bow and tilt have been documented [23,24], and are also used in our current studies to allow a precise measurement for shock velocity.

\section{Results and Conclusions}

\section{Shock-Velocity Determination}

The technique described in the earlier sections is designed to measure shock velocity. The shock front produced in the target will depend on the "shape" of the impactor as it strikes the surface of the target. Therefore, a convex or concave impactor will produce a convex or concave shock front. Figure 6 depicts the shock front arrival on both the A \& B planes. Notice that the time of closure resulting from tilt over an impact diameter of $13 \mathrm{~mm}$ is better than $12 \mathrm{~ns}$. Likewise the B plane fiber closure time indicates better than 6 ns closure over a diameter of $6.5 \mathrm{~mm}$.
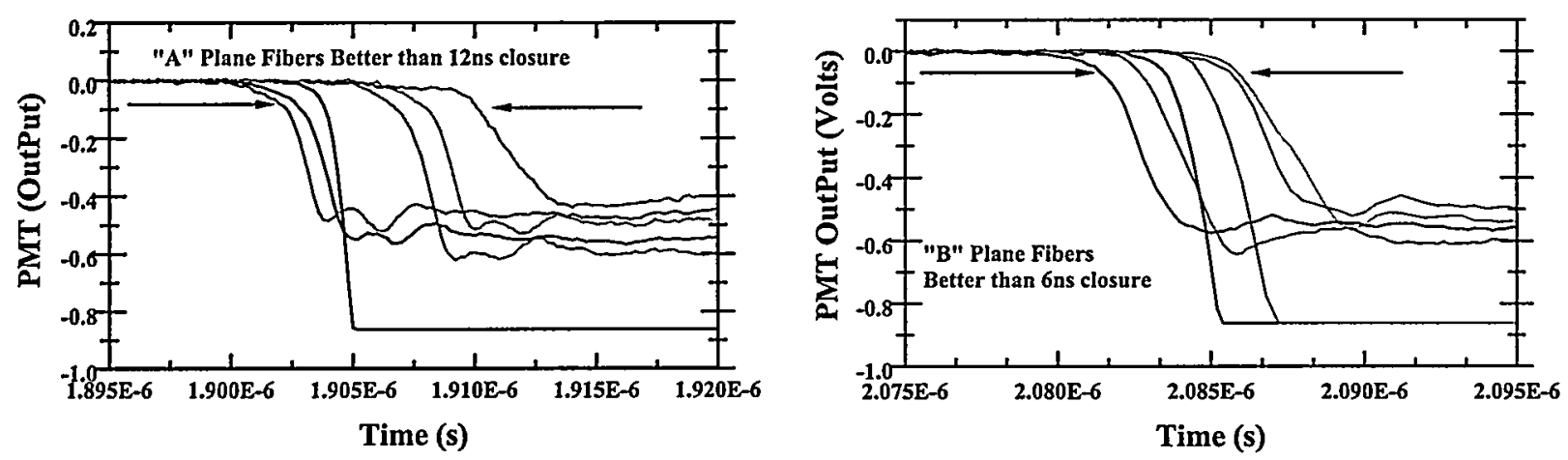

Figure 6. Typical Output of the photomultiplier tubes indicating the arrival of the shock front at the respective locations. Note the risetime of the output signals is about lns. 
Table III

\begin{tabular}{|l|l|c|c|c|c|c|c|c|}
\hline \multicolumn{1}{|c|}{ Shot } & Sensors & $\begin{array}{c}\mathbf{V}_{\mathbf{0}} \\
\mathbf{k m} / \mathbf{s}\end{array}$ & $\begin{array}{c}\mathbf{U}_{\mathbf{S}} \\
\mathbf{k m} / \mathbf{s}\end{array}$ & $\begin{array}{c}\mathbf{U}_{\mathfrak{p}} \\
\mathbf{k m} / \mathbf{s}\end{array}$ & $\begin{array}{c}\mathbf{P} \\
(\mathbf{G P a})\end{array}$ & $\boldsymbol{\varepsilon}$ & $\begin{array}{c}\text { Tilt } \\
(\mathbf{m r a d})\end{array}$ & $\begin{array}{c}\text { Bow } \\
(\mathbf{n s})\end{array}$ \\
\hline HVLTi7-P & & 9.77 & $10.44^{*}$ & & & 0.444 & & \\
\hline & Pins & & 10.616 & 4.737 & 222.239 & & 4.272 & $\sim 10$ \\
\hline & Fibers & & 10.564 & 4.746 & 221.569 & & 2.904 & $\sim 10$ \\
\hline HVLTi8-P & & 10.4 & $11.03^{*}$ & & & 0.459 & & \\
\hline & Pins & & 10.983 & 5.044 & 244.828 & & 5.303 & 4.718 \\
\hline & Fibers & & 11.074 & 5.028 & 246.060 & & 8.223 & 5.805 \\
\hline
\end{tabular}

${ }^{*}$ Average of two sensors

An analysis of the experimental records, indicated in Figure 6, suggests that the flyer is axially symmetric; the two circular arrays of needles produce the same tilt angle of the impactor (with respect to the target), and the impact distortion is parabolic. The data from the fibers indicate a flyer-plate bow of $5 \mathrm{~ns}$ and a corresponding tilt of about 8.5 milliradian. The precision of our diagnostic system is better than a nanosecond, which translates to a shock velocity measurement of approximately $11 \mathrm{~km} / \mathrm{s}$ to $+/-0.05 \mathrm{~km} / \mathrm{s}$ for this experiment.

Comparing the fiber-optic needle data with the anodized pin data that was on the same experiment provided redundancy while validating the new technology of using fiber-optic needles to obtain shock velocity. As shown in Table. III, the pin and needle shock velocity data was comparable for the tests that were performed. The different estimate for the times representing the bow is due to the difficulty of placing both an anodized pin and a fiber-optic needle at the center. This uncertainty is conjectured to be due to the inherent differences in the two types of time of arrival detectors diagnostic response with respect to each other.

Even though a limited number of experiments are indicated in this report, results of other experiments on other materials [25] do indicate that the shock velocity measurements are determined to an accuracy of better than $1-2 \%$.

\section{Particle-Velocity Determination}

As mentioned previously, to determine a complete EOS of a material, one needs to measure two physical quantities at high pressures. In this study, both shock velocity and particle velocity measurements are made. To determine the particle velocity, impedance matching technique [26] used. This is indicated in Figure 7. In the figure the common solution to the straight line $C A$ and the Hugoniot for warm Ti-6Al-4V centered at $V_{I}$ is solved to obtain the particle velocity $u_{p}$ in the material resulting from impact. These results are shown in Table III. Using the Rankine-

Hugoniot relations, one can determine the stress-volume relations from equations (6) and (7) as the following:

$$
\begin{aligned}
& P=\rho_{0} U_{s} u_{p} \\
& V=V_{o}\left[1-\left(u_{p} / U_{s}\right)\right]
\end{aligned}
$$

These results are summarized in figures $8 ; 9$, and 10 as $\mathbf{U}_{\mathbf{s}}-\mathbf{u}_{\mathbf{p}}, \mathbf{P}-\mathbf{u}_{\mathbf{p}}$, or $\mathbf{P}-\mathbf{V}$ relations. A linear least square's fit from the data shown in Figure 8, can be expressed as;

$$
\mathrm{U}_{\mathrm{s}}=4.816+1.195 \mathrm{u}_{\mathrm{p}}
$$


The current $\mathbf{U}_{\mathrm{s}}$ and impact velocity is determined to an accuracy of approximately $1.0 \%$. This

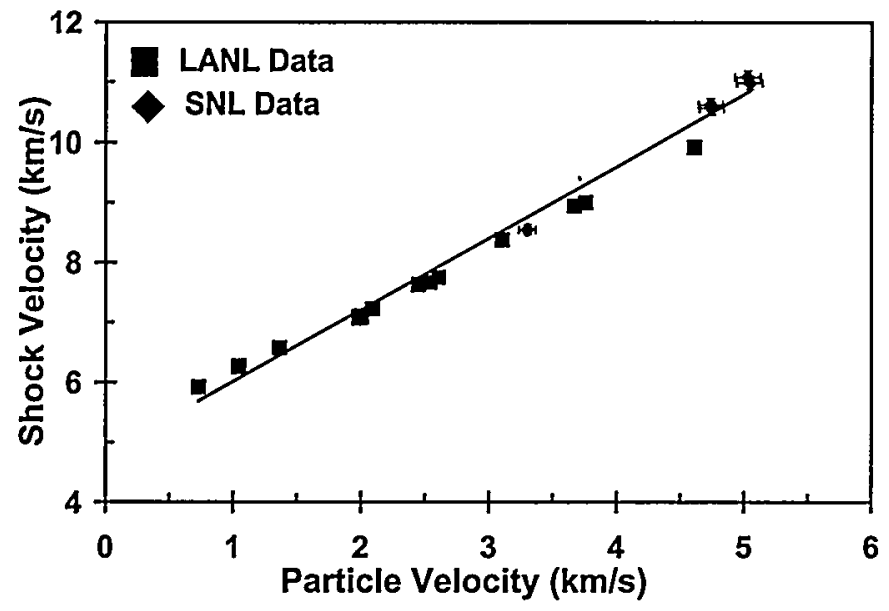

Figure 8. Shock velocity - particle velocity relationship

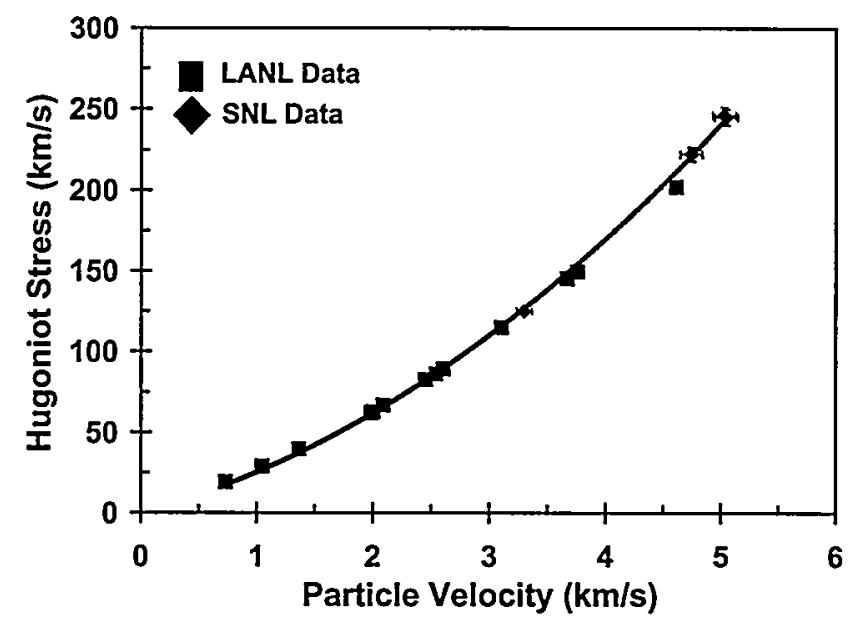

Figure 9. Pressure - particle velocity relationship

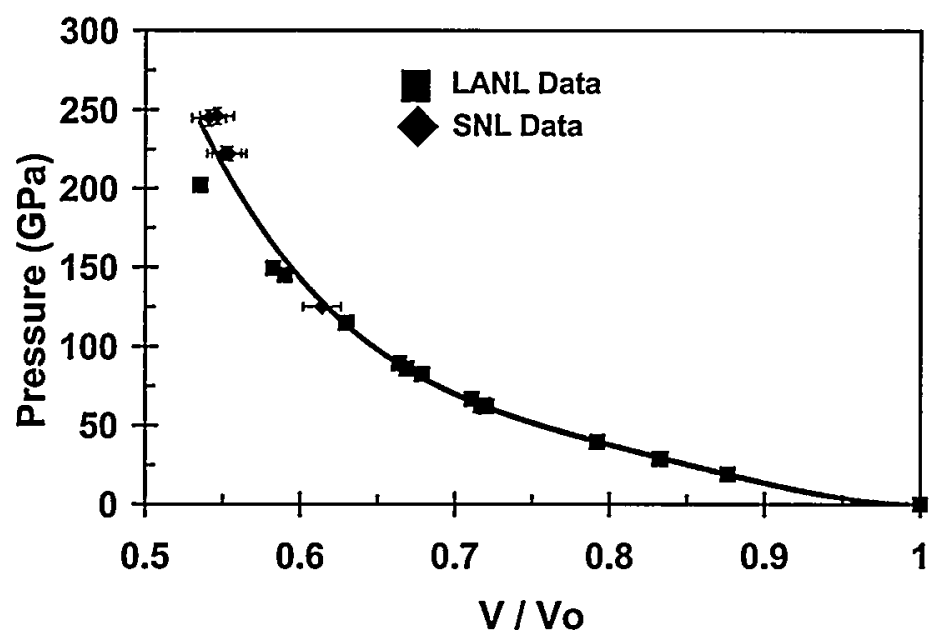

Figure 10. Pressure - Volume relationship

limits the particle velocity determination to an accuracy of approximately $2.0 \%$. Future improvements to the technology will focus upon determining the impact velocity directly during the experiment. This will, however, require that the sample dimensions be smaller than those used in our current investigation. This can be done by improvements in the time-resolution of the time-of-arrival detectors either by using streak camera recording devices or complimenting hose studies with the use of a continuous Line VISAR. Increasing the precision to better than a factor of two appears easily attainable.

To summarize, a technique has been developed to estimate the equation of state of materials using the three-stage light-gas gun also referred to as the Hypervelocity Launcher in the literature. In this study we are reporting the first EOS measurements of materials at impact velocities to better than $11 \mathrm{~km} / \mathrm{s}$. 


\section{REFERENCES}

1. M. D. Furnish, L. C. Chhabildas, W. D. Reinhart, (1999). Time-resolved particle velocity measurements at impact velocities of 10km/s. Int'l. J. of Impact Engng., 23, 261-270.

2. R. M. Brannon, L. C. Chhabildas, (1995). Experimental and Numerical Investigation of ShockInduced Vaporization in Zinc. Int'1. J. of Impact Engng., 17, 109-120.

3. L. C. Chhabildas, J. E. Dunn, W. D. Reinhart, and J. M. Miller, (1993). An impact technique to accelerate flyer-plate to velocities to over $12 \mathrm{~km} / \mathrm{s}$. Int'l. J. of Impact Engng., 14, 121-132.

4. L. C. Chhabildas, L. N. Kmetyk, W. D. Reinhart, and C. A. Hall, (1995). Enhanced hypervelocity launcher - capbilities to $16 \mathrm{~km} / \mathrm{s}$. Int'l. J. of Impact Engng., 17, 183-194.

5. A. C. Charters, (1987). Development of the high-velocity gas-dynamic gun. Int'l. J. of Impact Engng., 5, 181-203.

6. J. R. Asay, L. C. Chhabildas, and L. M. Barker, (1985). Projectile and impactor designs for plateimpact experiments. Sandia National Laboratories report, SAND85-2009, unpublished.

7. Chhabildas, L., C., and Graham R., A., Developments in Measurement Techniques for ShockLoaded Solids, Presented at the 1987 ASME Applied Mechanics, Bioengineering Conference, AMD-Vol. 83, June 14-17, 1987

8. L. M. Barker, and R.E. Hollenback, Laser Interferometer for Measuring High Velocities of any Reflecting Surface, Journal of Applied Physics 43, 4669, 1972.

9. L. C. Chhabildas, L. M. Barker, J. R. Asay, T. G. Trucano, G. I. Kerley, J. E. Dunn, Launch Capabilities to over $10 \mathrm{~km} / \mathrm{s}$, in Shock Waves of Condensed Matter-1991 (S. C. Schmidt, R. D. Dick, J. W. forbes and D. G. Tasker, eds), 1025-1031, Elsevier Science Publishers (1992).

10. M. B. Boslough, J. A. Ang, L. C. Chhabildas, W. D. Reinhart, C. A. Hall, B. G. Cour-Palais, E. L. Christiansen, and J. L. Crews, Hypervelocity Testing of Advanced Shielding Concepts for Spacecraft against Impacts to $10 \mathrm{~km} / \mathrm{s}$, Int'l. J. of Impact Engng., 14, 95-106, )1993.

11. L. C. Chhabildas, and L. M. Barker, J. R. Asay, T. G. Trucano, Relationship of Fragment Size to Normalized Spall Strength for Materials, Int'1. J. of Impact Engng., 10, 107-124. (1990)

12. L. C. Chhabildas, J. R. Asay, Dynamic Yield Strength and Spall Strength Measurments Under Quasi-Isentropic Loading, Shock Waves and High Strain-Rate Phenomena in Materials (M. A. Myers, L. E. Murr and K. P. Staudhammer, eds), pp.947-955, Marcel Decker, New York (1992) 947.

13. L. M. Barker, High Pressure, Quasi-Isentropic Impact Experiments, Shock Waves in Condensed Matter-1983 (J. R. Asay, R. A. Grahmn, and G. K. Straub, eds), pp. 217-224, Elsvier Science Publishers (1984).

14. Sandia National laboratory, Internal Memo, C. H. Konrad, Analysis for the Sandia National Laboratories (SNL) Optical Beam Reflectance (OBR) Technique, 1999 memo.

15. University of California, Lawrence Livermore National Laboratory, N. C. Holmes, Analysis of Errors for Optical Beam reflective Data for JASPER, 1999 memo.

16. L. C. Chhabildas and J. R. Asay, Rise-Time Measurements of Shock Transitions in Aluminum, Copper, and Steel, Journal of Applied Physics, 50, 2749 (1979)

17. G. I. Kerley, BCAT User's Manual and Input Instructions, Ver 1.10, 1999.

18. J. N. Fritz, C. E. Morris, R. Hixson, Private Communication, 1999.

19. Metallic Materials And Elements For Aerospace Vehicle Structures, MIL-HDBK-5H, December 1998.

20. J. R. Asay, M. Shahinpoor (eds), High Pressure Shock Compression of Solids, 1993 
21. L. R. Veeser, M. J. George, R. Menikoff, B. Papatheofanis, Sensing of High Pressure by Shock Heating Quartz Optical Fibers, SPIE, Vol. 838, Fiber Optic and Laser Sensors V(1987)

22. L. R. Veeser, J. Stokes, Fiber Optic Diagnostics for High Explosives, Paper submitted to DNA Conference on Instrumentation for Nuclear Weapons Effects Testing, Nov., 1993, LA-CP-93232.

23. A. C. Mitchell and W. J. Nellis, Journal of Applied Physics, 52, 3 (Mar. 1981)

24. A. C. Mitchell and W. J. Nellis, Journal of Applied Physics, 52, 5 (May., 1981)

25. L. C. Chhabildas, private communication.

26. R. Kinslow (ed), High Velocity Impact Phenomena, 1970

27. T. F. Thornhill, L.C. Chhabildas, W. D. Reinhart "Accurate Velocity Measurements pof the Two-Stage Gun Projectile", Proceedings of the $51^{\text {st }}$ Aeroballistic Range Association Meeting, Madrid Spain, 2000

*This work was supported by the U. S. Department of Energy under contract DE-AC04-94AL85000. Sandia is a multiprogram laboratory operated by Sandia Corporation a Lockheed Martin Company, for the United States Department of Energy. 